Mar. Drugs 2010, 8, 2162-2174; doi:10.3390/md8072162

\title{
Bromopyrrole Alkaloids as Lead Compounds against Protozoan Parasites
}

Fernando Scala ${ }^{1}$, Ernesto Fattorusso ${ }^{1}$, Marialuisa Menna ${ }^{1}$, Orazio Taglialatela-Scafati ${ }^{1{ }^{*} \text {, }}$ Michelle Tierney $^{2}$, Marcel Kaiser ${ }^{3,4}$ and Deniz Tasdemir ${ }^{2, *}$

1 Dipartimento di Chimica delle Sostanze Naturali, Università di Napoli "Federico II", Via D. Montesano, 49, I-80131, Napoli, Italy; E-Mails: fernando.scala@ unina.it (F.S.); fattoru@unina.it (E.F.); mlmenna@unina.it (M.M.)

2 Department of Pharmaceutical and Biological Chemistry, School of Pharmacy, University of London, 29-39 Brunswick Square, London WC1N 1AX, UK;

E-Mail: michelle.tierney@ymail.com (M.T.)

3 Department of Medical Parasitology and Infection Biology, Swiss Tropical Institute, Socinstr. 57, CH-4002, Basel, Switzerland; E-Mail: marcel.kaiser@unibas.ch (M.K.)

4 University of Basel, Petersplatz 1, CH-4051 Basel, Switzerland

* Authors to whom correspondence should be addressed; E-Mails: scatagli@ unina.it (O.T.-S.); deniz.tasdemir@pharmacy.ac.uk (D.T.); Tel.: +39-081-678509 (O.T.-S.); +44-20-7753-5845 (D.T.); Fax: +3-081-678552 (O.T.-S.); +44-20-7753-5909 (D.T.).

Received: 7 June 2010; in revised form: 24 June 2010 / Accepted: 9 July 2010 /

Published: 14 July 2010

Abstract: In the present study, 13 bromopyrrole alkaloids, including the oroidin analogs hymenidin (2), dispacamide B (3) and dispacamide D (4), stevensine (5) and spongiacidin B (6), their derivatives lacking the imidazole ring bromoaldisin (7), longamide B (8) and longamide A (9), the dimeric oroidin derivatives sceptrin (10) and dibromopalau'amine (11), and the non-oroidin bromopyrrolohomoarginin (12), manzacidin A (13), and agelongine (14), obtained from marine sponges belonging to Axinella and Agelas genera have been screened in vitro against four parasitic protozoa, i.e., two Trypanosoma species (T. brucei rhodesiense and T. cruzi), Leishmania donovani and Plasmodium falciparum (K1 strain, a chloroquine resistant strain), responsible of human diseases with high morbidity and, in the case of malaria, high mortality. Our results indicate longamide B (8) and dibromopalau'amine (11) to be promising trypanocidal and antileishmanial agents, while dispacamide B (3) and spongiacidin B (6) emerge as antimalarial lead compounds. In addition, evaluation of the activity of the test alkaloids (2-14) against three different 
enzymes (PfFabI, PfFabG, PfFabZ) involved in the de novo fatty acid biosynthesis pathway of $P$. falciparum (PfFAS-II) identified bromopyrrolohomoarginin (12) as a potent inhibitor of $P f F a b Z$. The structural similarity within the series of tested molecules allowed us to draw some preliminary structure-activity relationships. Tests against the mammalian L6 cells revealed important clues on therapeutic index of the metabolites. This is the first detailed study on the antiprotozoal potential of marine bromopyrrole alkaloids.

Keywords: bromopyrrole alkaloids; antiprotozoal activity; enzyme inhibition; Trypanosoma; Leishmania; Plasmodium

\section{Introduction}

Diseases caused by single-celled protozoal parasites affect about one billion people with a particular incidence in tropical countries. The major contribution to these dramatic numbers is given by malaria, caused by protozoa belonging to the genus Plasmodium (P. falciparum, P. ovale, P. vivax, $P$. malariae), with $P$. falciparum being responsible for most severe forms of the disease and most fatal cases. The improvement of hygienic conditions, the massive use of insecticides, and the discovery of different drugs played a great role in the nearly complete extinction of malaria in developed countries. Unfortunately, malaria is still a common cause of death (approximately one million per year) in the tropical countries of Africa, Asia and America, and tragically most of the victims are children under the age of five: every 30 seconds a child dies of malaria [1]. The increase in the number of fatal cases registered in recent years is principally due to the spread of mosquitoes resistant to common insecticides and, more importantly, the emergence of multi-drug resistant strains of Plasmodium. The latter problem makes many of the available drugs useless, leaving some efficacy only to the artemisinin-based therapies. Since malaria is a disease of worldwide implications and almost half of the world's population is currently at risk for malaria infection, combating malaria is one of the highest priority programs of the WHO.

The mortality of the remaining protozoal diseases is much less marked (nearly 100,000 deaths per year) but their morbidity is also extremely high, severely affecting the quality of life of infected people. African trypanosomiasis (sleeping sickness) is caused by Trypanosoma brucei gambiense and T. brucei rhodesiense, which invade the central nervous system, leading to behavioural changes, coma, and ultimately, if untreated, death [2]. Chagas' disease is caused by $T$. cruzi with the vector contribution of a blood-sucking insect (triatome), which bites the victim and contaminates the wound with infected feces. The disease, which is also known as South American trypanosomiasis, is one of the major health problems in Latin America. Leishmaniasis is caused by over 20 species of intracellular parasites from the genus Leishmania, which are transmitted to humans by sand flies. This disease can give different clinical symptoms including cutaneous, mucosal, and visceral forms [3]. Both the cutaneous and mucosal forms can cause severe deformities to patients, including ulcerative skin lesions and the destruction of mucous membranes, in some cases leading to permanent disfigurement. The visceral form of the disease, caused principally by L. donovani, L. infantum, and 
L. chagasi, represents the greatest threat to human health, with symptoms ranging from fever and weight loss to hepatosplenomegaly, leading to death in untreated cases [4].

The chemotherapeutic options to control and treat these protozoal infections are dramatically limited to few classes of drugs which, in many cases, are associated with severe toxicity and variable efficacy. The unaffordable cost of many treatments (e.g., amphotericin B is very effective in leishmaniasis but it is too expensive) and the emerging resistance against these drugs make discovery and development of new, safe and effective antiprotozoal agents a pressing need. In this regard, marine organisms constitute an universally recognized source of potentially bioactive molecules, which have been enzymatically engineered and biologically validated. Marine invertebrates, such as sponges, have an incredible potential to produce a large array of secondary metabolites, belonging to different structural classes, often through the biosynthetic contribution of microorganisms harbored in their tissues. In a recent review, we have collected the most promising classes of marine antimalarial lead compounds [5], while a number of other reviews can give an account of the activity of compounds originated from marine organisms against other protozoa [6].

Bromopyrrole alkaloids are a well known class of sponge metabolites, and oroidin (1a,b) is regarded as the parent compound for this type of compounds. We recently reported the antiprotozoal activity of oroidin base (1a), oroidin TFA salt (1) $)$, as well as the structurally simpler 4,5-dibromopyrrole-2-carboxylic acid and 3-amino-1-(2-aminoimidazoyl)-prop-1-ene, all obtained from a Turkish Agelas oroides specimen [7]. In addition, both oroidin forms were found to inhibit a key enzyme, $P f F a b I$ (enoyl-ACP reductase), of the plasmodial type II fatty acid biosynthesis pathway (PfFAS-II) [7]. The de novo PfFAS-II pathway, which was identified in P. falciparum in 1998 [8], was originally thought to be operated in the blood stage forms of the malaria parasite [9]. However, very recent studies suggest that the pathway is indispensible for the liver stage, which precedes the blood stage in humans, hence it is a very good target for malaria prophylaxis [10,11]. Stimulated by the data on oroidin, we decided to evaluate the antiprotozoal activity of 13 bromopyrrole alkaloids (2-14, Figure 1), all isolated as free bases from Mediterranean marine sponges belonging to Agelas and Axinella genera. The compounds were also tested against PfFabI as well as against two additional enzymes involved in PfFAS-II pathway of $P$. falciparum, PfFabG ( $\beta$-ketoacyl-ACP reductase) and PfFabZ ( $\beta$-hydroxyacyl-ACP dehydratase). The test compounds belong to different subclasses, including oroidin analogs as hymenidin (2), dispacamide B (3), dispacamide D (4), stevensine (5), and spongiacidin B (6), and their derivatives lacking the imidazole ring, such as bromoaldisin (7), longamide B (8) and longamide A (9), and, finally, dimeric oroidin derivatives as sceptrin (10) and dibromopalau'amine (11). Three non-oroidin bromopyrrole alkaloids as bromopyrrolohomoarginin (12), manzacidin A (13), and agelongine (14) have been also tested. To our knowledge this is the first study assessing the antiprotozoal activity of marine bromopyrrole alkaloids in detail.

\section{Results and Discussion}

The bromopyrrole alkaloids 2-14 were evaluated in vitro against the mammalian stages of four parasitic protozoa: Trypanosoma brucei rhodesiense (bloodstream forms), T. cruzi (intracellular amastigotes in L6 rat skeletal myoblasts), Leishmania donovani (axenic amastigotes), and Plasmodium falciparum (erythrocytic stage of K1 strain, a chloroquine and pyrimethamine resistant strain). The 
toxicity on mammalian cells was assessed against L6 cells, a primary cell line derived from rat skeletal myoblasts.

Figure 1. The chemical structures of bromopyrrole alkaloids 1-14.<smiles>[Y]C([Y])C/C=C/c1cnc(N)[nH]1</smiles>

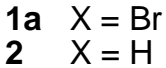<smiles>[R]C(/C=C1\NC(N)=NC1=O)CNC(=O)c1cc(Br)c[nH]1</smiles>

$\begin{array}{ll}3 & \mathrm{R}=\mathrm{H} \\ 4 & \mathrm{R}=\mathrm{OH}\end{array}$<smiles>[X]c1[nH]c(C(=O)NC/C=C/c2c[nH]c(=N)[nH]2)cc1Br</smiles>

$1 \mathrm{~b}$<smiles>Nc1ncc(C2=CCNC(=O)c3[nH]c(Br)c(Br)c32)[nH]1</smiles>

5<smiles>NC1=NC(=O)/C(=C2\CCNC(=O)c3[nH]cc(Br)c32)N1</smiles>

6<smiles></smiles>

$\mathrm{Br}$<smiles>Nc1nc(C2[C@@H](CNC(=O)c3cc(Br)c[nH]3)C(CNC(=O)c3cc(Cl)c[nH]3)[C@H]2c2cnc(N)[nH]2)c[nH]1</smiles>

10<smiles>N=C(N)NCCCC[C@H](NC(=O)c1cc(Br)c[nH]1)C(=O)O</smiles>

12<smiles>O=C(O)CC1CNC(=O)c2cc(Br)c(Br)n21</smiles>

8<smiles>O=C1NC[C@@H](O)n2c1cc(Br)c2Br</smiles>

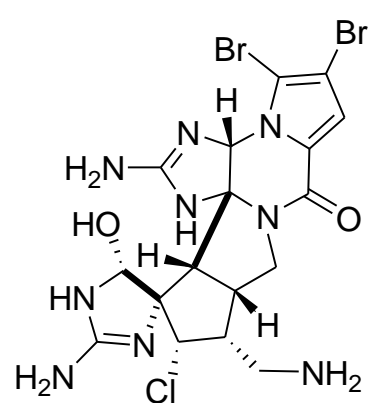

11<smiles>CC1(COC(=O)c2cc(Br)c[nH]2)C[C@@H](C(=O)O)N=CN1</smiles><smiles>O=C([O-])c1ccc[n+](CCOC(=O)c2cc(Br)c[nH]2)c1</smiles>

14

Results compiled in Table 1 show that all compounds, except longamide A (9), displayed some activity against African trypanosome, T. brucei rhodesiense. The highest inhibition activity against this parasite was shown by dibromopalau'amine (11) $\left(\mathrm{IC}_{50}=0.46 \mu \mathrm{g} / \mathrm{mL}\right)$, followed by longamide $\mathrm{B}(\mathbf{8})$ 
$\left(\mathrm{IC}_{50}=1.53 \mu \mathrm{g} / \mathrm{mL}\right)$, and then by sceptrin $(\mathbf{1 0})\left(\mathrm{IC}_{50}=9.71 \mu \mathrm{g} / \mathrm{mL}\right)$ and spongiacidin $\mathrm{B}(\mathbf{6})$ $\left(\mathrm{IC}_{50}=13.58 \mu \mathrm{g} / \mathrm{mL}\right)$. The potency of the remaining alkaloids was moderate $(25.35$ to $77.64 \mu \mathrm{g} / \mathrm{mL})$. The activity against American trypanosome, T. cruzi, was much less pronounced or completely absent even at the highest test concentrations $(90 \mu \mathrm{g} / \mathrm{mL})$. Interestingly, the compounds with the highest T. b. rhodesiense activity (dibromopalau'amine (11), longamide B (8), sceptrin (10), and spongiacidin B (6)) plus hymenidin (2) were also the only low active alkaloids against T. cruzi ( IC $_{50}$ values $>33.03 \mu \mathrm{g} / \mathrm{mL}$ ).

The majority of alkaloids also showed growth inhibition activity against Leishmania donovani and the most remarkable activity was shown by dibromopalau'amine (11) $\left(\mathrm{IC}_{50}\right.$ value $\left.1.09 \mu \mathrm{g} / \mathrm{mL}\right)$ and longamide $\mathrm{B}(\mathbf{8})\left(\mathrm{IC}_{50}=3.85 \mu \mathrm{g} / \mathrm{mL}\right)$. These activities are quite interesting since they fall almost in the same order of potency of the reference compound, miltefosine $\left(\mathrm{IC}_{50}=0.21 \mu \mathrm{g} / \mathrm{mL}\right)$. All the other alkaloids were much less active than $\mathbf{1 1}$ and $\mathbf{8}$, while three compounds, dispacamide B (2), bromoaldisin (7), and longamide A (9), were completely inactive.

Except for dispacamide D (4), bromoaldisin (7) longamide A (9) and manzacidin A (13), all the tested bromopyrrole alkaloids showed antiplasmodial activity against the multiple-drug resistant $\mathrm{K} 1$ strain of $P$. falciparum. The most potent compounds were spongiacidin B $(6)\left(\mathrm{IC}_{50}=1.09 \mu \mathrm{g} / \mathrm{mL}\right)$, dispacamide $\mathrm{B}(\mathbf{3})\left(\mathrm{IC}_{50}=1.34 \mu \mathrm{g} / \mathrm{mL}\right)$ and dibromopalau'amine $(\mathbf{1 1})\left(\mathrm{IC}_{50}=1.48 \mu \mathrm{g} / \mathrm{mL}\right)$, all of them exhibiting a significant activity in the very low $\mu \mathrm{g} / \mathrm{mL}$ range. In comparison to the other parasites, the $\mathrm{IC}_{50}$ values of the remaining active alkaloids against $P$. falciparum were smaller $(1.09-12.54 \mu \mathrm{g} / \mathrm{mL})$.

When tested against mammalian (L6) cells (Table 1), only dibromopalau'amine (11) and longamide B (8) appeared to be associated with some toxicity $\left(\mathrm{CC}_{50}\right.$ values of 4.46 and $9.94 \mu \mathrm{g} / \mathrm{mL}$, respectively). The selectivity index (SI, calculated by dividing the $\mathrm{CC}_{50}$ value against $\mathrm{L} 6$ cells to the $\mathrm{IC}_{50}$ value against the parasite) of dibromopalau'amine (11) for T. brucei rhodesiense was about 10 . However, the SI values for $L$. donovani or P. falciparum were around 3-4, indicating a narrow therapeutic window. The $\mathrm{CC}_{50}$ values of longamide $\mathrm{B}(\mathbf{8})$ against mammalian cells were not much higher than its $\mathrm{IC}_{50}$ values against $T$. brucei rhodesiense and $L$. donovani, again implying low selectivity indices (6.5 for T. brucei rhodesiense, and 2.6 against $L$. donovani). On the contrary, the $\mathrm{CC}_{50}$ value of spongiadicin $\mathrm{B}$ (6) towards L6 cells is about 30-times higher $\left(\mathrm{CC}_{50}=35.6 \mu \mathrm{g} / \mathrm{mL}\right)$ than that against $P$. falciparum, while dispacamide $\mathrm{B}$ is devoid of any cytotoxicity at the highest test concentration $(90 \mu \mathrm{g} / \mathrm{mL})$. These data unambiguously suggested that spongiacidin B (6) and dispacamide B (3) exhibited a selective antiplasmodial activity with $\mathrm{IC}_{50}$ values of 1.34 and $1.09 \mu \mathrm{g} / \mathrm{mL}$ and SI values of 32.7 and $>67.2$, respectively.

Stimulated by data about the inhibitory activity of oroidin (1) against the P. falciparum PfFabI enzyme [7], we evaluated the activity of all the bromopyrrole alkaloids $\mathbf{2}-\mathbf{1 4}$ against three key enzymes involved in the fatty acid pathway (FAS-II) of P. falciparum, namely PfFabI, PfFabG and $P f$ FabZ. None of the test compounds showed activity $\left(\mathrm{IC}_{50}>30 \mu \mathrm{g} / \mathrm{mL}\right)$ against $P f F a b I$ and $P f F a b G$, while a single compound, namely bromopyrrolohomoarginin (12), showed a very significant activity $\left(\mathrm{IC}_{50}=0.28 \mu \mathrm{g} / \mathrm{mL}\right)$ against PfFabZ. Since this activity is identical with that of the reference compound, (-)-epigallocatechin gallate $\left(\mathrm{IC}_{50}=0.32 \mu \mathrm{g} / \mathrm{mL}\right)$, it is surely worthy of further investigation. 
Table 1. In vitro antiprotozoal and cytotoxic activities of bromopyrroles 1-14. The $\mathrm{IC}_{50}$ (protozoa) and $\mathrm{CC}_{50}$ (L6 cells) values are in $\mu \mathrm{g} / \mathrm{mL}$ and represent the average of at least two independent assays performed in duplicates.

\begin{tabular}{c|c|c|c|c|c}
\hline Compound & $\begin{array}{c}\boldsymbol{T} . \boldsymbol{b} . \\
\text { rhodesiense }\end{array}$ & $\begin{array}{c}\boldsymbol{T} . \\
\text { cruzi }\end{array}$ & $\begin{array}{c}\text { L. } \\
\text { donovani }\end{array}$ & $\begin{array}{c}\boldsymbol{P} . \\
\text { falciparum }\end{array}$ & $\begin{array}{c}\text { Cytotoxicity } \\
\text { L6 cells }\end{array}$ \\
\hline $\mathbf{1 a}$ & $17.30^{1}$ & $>30^{1}$ & $>30^{1}$ & $3.90^{1}$ & $88.60^{1}$ \\
$\mathbf{1 b}$ & $12.20^{1}$ & $>30^{1}$ & $15.40^{1}$ & $7.90^{1}$ & $76.40^{1}$ \\
$\mathbf{2}$ & 77.64 & 73.10 & 29.87 & 12.54 & 75.73 \\
$\mathbf{3}$ & 40.12 & $>90$ & $>90$ & $\mathbf{1 . 3 4}$ & $>90$ \\
$\mathbf{4}$ & 68.25 & $>90$ & 53.75 & $>20$ & $>90$ \\
$\mathbf{5}$ & 25.34 & $>90$ & 75.86 & 4.88 & $>90$ \\
$\mathbf{6}$ & 13.48 & 72.25 & 41.59 & $\mathbf{1 . 0 9}$ & 35.61 \\
$\mathbf{7}$ & 61.48 & $>90$ & $>90$ & $>20$ & $>90$ \\
$\mathbf{8}$ & $\mathbf{1 . 5 3}$ & 33.03 & $\mathbf{3 . 8 5}$ & 7.46 & $\mathbf{9 . 9 4}$ \\
$\mathbf{9}$ & $>90$ & $>90$ & $>90$ & $>20$ & $>90$ \\
$\mathbf{1 0}$ & 9.71 & 60.08 & 51.58 & 11.08 & $>90$ \\
$\mathbf{1 1}$ & $\mathbf{0 . 4 6}$ & 68.88 & $\mathbf{1 . 0 9}$ & $\mathbf{1 . 4 8}$ & $\mathbf{4 . 4 6}$ \\
$\mathbf{1 2}$ & 67.13 & $>90$ & 34.49 & $>20$ & 62.32 \\
$\mathbf{1 3}$ & 73.76 & $>90$ & 75.83 & $>20$ & $>90$ \\
$\mathbf{1 4}$ & 49.96 & $>90$ & 43.22 & 11.18 & $>90$ \\
\hline Standards & $0.004^{\mathrm{a}}$ & $0.312^{\mathrm{b}}$ & $0.206^{\mathrm{c}}$ & $0.065^{\mathrm{d}}$ & $0.005^{\mathrm{e}}$ \\
\hline
\end{tabular}

Standard compounds: ${ }^{\mathrm{a}}$ Melarsoprol, ${ }^{\mathrm{b}}$ Benznidazole, ${ }^{\mathrm{c}}$ Miltefosine, ${ }^{\mathrm{d}}$ Chloroquine, ${ }^{\mathrm{e}}$ Podophyllotoxin.

${ }^{1}$ These results are from our earlier study [7].

Bromopyrrole alkaloids constitute a family of typically marine alkaloids and represent a fascinating example of the chemical diversity of secondary metabolites elaborated by marine invertebrates. Indeed, about 160 members of this class have been isolated so far from more than 20 different sponges of various genera, essentially belonging to Agelasidae, Axinellidae, and Halichondridae families. Oroidin (1a,b) is considered the parent compound of this family and many bromopyrrole alkaloids possessing a pyrrole-imidazole structure can be conceived as derivatives of the $\mathrm{C}_{11} \mathrm{~N}_{5}$ skeleton of oroidin. In a recent review [12], we have proposed the following classification of these alkaloids according to their structures: (a) oroidin-like linear monomers; (b) polycyclic oroidin derivatives (including six different oroidin cyclization modes); (c) simple or rearranged oroidin-like dimers or higher oligomers; (d) non-oroidin bromopyrrole alkaloids. In the current study, all the above structural classes of bromopyrrole alkaloids were represented. Indeed, hymenidin (2), dispacamides B (3) and D (4) belong to the class of oroidin-like linear monomers; stevensine (5) and spongiacidin B (6) belong to the class of polycyclic oroidin derivatives; sceptrin (10) and dibromopalau'amine (11) are oroidinlike dimers [13], while the six remaining alkaloids $(\mathbf{7 - 9}, \mathbf{1 2}-\mathbf{1 4})$ belong to the class of non-oroidin bromopyrroles, although some of them (7-9) appear to be strictly related to oroidin-like compounds, from which they differ for the lack of the imidazole ring. Manzacidin A (13) and agelongine (14) are characterized by an ester linkage in place of the amide linkage between the bromopyrrole unit and the remaining part of the molecule.

The interest in bromopyrrole alkaloids has been particularly raised by the number of different promising bio/pharmacological activities associated with them. Focusing on compounds evaluated in 
the present study: dispacamides $(\mathbf{3 , 4})$ have been reported to possess a selective anti-histamine activity [14,15]; hymenidin (2) [16] and agelongine (14) [17] were reported as anti-serotonergic agents; dibrompalau'amine (11) showed immunosuppressive properties [18]; sceptrin (10) proved to be an antibacterial and antifungal agent [19]. A very recent study reports on its inhibitory activity on the cell motility of several cancer cell lines, without cytotoxicity, with potential application in human diseases as cancer and chronic inflammation [20].

In the present study, a reasonable number of bromopyrrole alkaloids have been tested for growth inhibitory activity against a panel of parasitic protozoa. In the first glance, the detected antiprotozoal activities do not appear to be associated to a specific structural class. For example, a good inhibitory activity against Trypanosoma brucei rhodesiense and Leishmania donovani has been shown by an oroidin dimer (dibromopalau'amine) (11) and by a non-oroidin alkaloid (longamide B) (8). However, there are some conclusions to be drawn for the growth inhibitory activities of the metabolites towards these two parasites. Oroidin (1a) or its TFA salt (1) $)$, which contain two bromine atoms on the pyrrole ring are more active [7] than the related monobromo compounds $\mathbf{2}-\mathbf{4}$. This might indicate the importance of two $\mathrm{Br}$ atoms on adjacent pyrrole carbons for activity against $T$. brucei rhodiense and Leishmania. The most active trypanocidal and leishmanicidal compounds are an oroidin dimer (dibromopalau'amine (11) and a non-oroidin alkaloid (longamide B) (8). The existence of two bromine groups in $\mathbf{1 1}$ might have some impact on its bioactivity. The second most active compound longamide B (8) differs from the inactive longamide A (9), which was completely inactive against any protozoan parasite, by the presence of a carboxymethyl function. It appears that this group might also be responsible for the cytotoxicity of $\mathbf{8}$, since $\mathbf{9}$ is also non-toxic.

The best antimalarial activity has been exhibited by a linear oroidin-like compound (dispacamide B) (3), by a polycyclic oroidin derivative (spongiacidin B) (6), and by an oroidin dimer (dibromopalau'amine) (11). The structural similarity within the series of molecules tested in this study allows the formulation of some preliminary structure-activity relationships also for the antimalarial activity. The two most potent antimalarial alkaloids, dispacamide B (3) and spongiacidin B (6) show an oroidin-like structure with oxidation of the aminoimidazole to aminoimidazolone (alkylidene glycocyamidine) ring. The clear positive impact of this structural feature becomes even more obvious when these compounds are compared with closely related analogs. The much less active hymenidin (2) differs from dispacamide B (3) just by the oxidation of the aminoimidazole ring. The same relationship connects spongiacidin B (6) and stevensine (5), which is almost five-times less active than the former. Moreover, when compared with oroidin, both compounds $\mathbf{3}$ and $\mathbf{6}$ appear to display better antimalarial potency (Table 1). The low activity of dispacamide D (4) indicates that the presence of an hydroxyl group within the linear alkyl chain is unfavorable for the antimalarial activity. The comparison of antimalarial potencies of spongiacidin B (6) and bromoaldisin (7) clearly indicates that the imidazoletype ring must play a pivotal role for the antimalarial activity.

The malaria parasite undergoes two life stages in the human body, a liver stage, followed by short cycles of the erythrocytic (blood) stage. Lately, the liver phase of the infection is gaining more attention as its inhibition provides a causal prophylaxis, i.e., prevents the blood stage infection and the clinical symptoms of the disease. It has been recently demonstrated that liver stage malaria parasites exhibit an absolute requirement for de novo FAS-II pathway. The deletion or inhibition of critical elongation enzymes such as FabI or FabZ enzymes results in the inability to cause a erythrocytic 
infection, hence death of the parasite [10,11]. Thus, FAS-II pathway has become an ideal target for malaria prophylaxis.

In a previous project, we identified both oroidin base (1a) and its salt (1b) as potent PfFAbI inhibitors [7]. In the current study, none of the compounds inhibited the PfFabI (enoyl-ACP reductase) enzyme. This again might indicate the importance of two $o$-positioned bromine atoms in oroidin-like compounds for $P f F a b I$ inhibitory activity. However, several compounds contain such functionality in their structures, suggesting that structural requirements to inhibit the PfFabI enzyme are likely to be more complex. Notably, only bromopyrrolohomoarginin (12), showed a very significant activity against another crucial PfFAS-II enzyme PfFabZ. Due to its inhibitory activity against this enzyme, compound 12 might have potential in malaria prophylaxis.

\section{Experimental Section}

\subsection{Isolation of compounds $\mathbf{2}-\mathbf{1 4}$}

Compounds 2-14 were isolated as free bases from different sponges belonging to the genera Agelas and Axinella, using different chromatographic techniques, as described previously, and characterized by means of spectroscopic techniques. Sceptrin (10), hymenidin (2), dispacamides B (3) and D (4) have been obtained from four different Agelas sponges (A. conifera, A. clathrodes, A. longissima, A. dispar) [14,15]. Stevensine (5), spongiacidin B (6), bromoaldisin (7), dibromopalau'amine (11), compound 12 and manzacidin A (13) have been obtained from Axinella verrucosa [21]. Longamide A (9) has been obtained from Agelas longissima [22], longamide B (8) has been obtained from Agelas dispar [23]. Agelongine (14) was initially obtained from Agelas longissima [17], however, it has been later found as component of the polar fractions of practically all the Agelas and Axinella species investigated in our laboratory so far. The purity of all these compounds (>95\%) was confirmed by ${ }^{1} \mathrm{H}$ - and ${ }^{13} \mathrm{C}-\mathrm{NMR}$.

\subsection{Activity against Plasmodium falciparum}

In vitro activity against erythrocytic stages of $P$. falciparum was determined by a modified $\left[{ }^{3} \mathrm{H}\right]$-hypoxanthine incorporation assay [24] using the chloroquine- and pyrimethamine-resistant $\mathrm{K} 1$ strain and the standard drug chloroquine. Briefly, parasite cultures incubated in RPMI 1640 medium with 5\% Albumax (without hypoxanthine) were exposed to serial drug dilutions in microtiter plates. After $48 \mathrm{~h}$ of incubation at $37{ }^{\circ} \mathrm{C}$ in a reduced oxygen atmosphere, $0.5 \mu \mathrm{Ci}{ }^{3} \mathrm{H}$-hypoxanthine was added to each well. Cultures were incubated for a further $24 \mathrm{~h}$ before they were harvested onto glass-fiber filters and washed with distilled water. The radioactivity was counted using a Betaplate ${ }^{\mathrm{TM}}$ liquid scintillation counter (Wallac, Zurich, Switzerland). The results were recorded as counts per minute (CPM) per well at each drug concentration and expressed as percentage of the untreated controls. $\mathrm{IC}_{50}$ values were calculated from graphically plotted dose-response curves. Each $\mathrm{IC}_{50}$ value obtained is the mean of at least two separate experiments performed in duplicate (the variation is maximum 20\%). 


\subsection{Activity against Trypanosoma brucei rhodesiense}

STIB 900 strain of $T . b$. rhodesiense and the standard drug melarsoprol were used for the assay [25]. Minimum Essential Medium $(50 \mu \mathrm{L})$ supplemented with $25 \mathrm{mM}$ HEPES, $1 \mathrm{~g} / \mathrm{L}$ additional glucose, 1\% MEM non-essential amino acids (100×), $0.2 \mathrm{mM}$ 2-mercaptoethanol, $1 \mathrm{mM}$ Na-pyruvate and $15 \%$ heat inactivated horse serum was added to each well of a 96-well microtiter plate [26]. Serial drug dilutions of seven 3-fold dilution steps covering a range from 90 to $0.123 \mu \mathrm{g} / \mathrm{mL}$ were prepared. Then $10^{4}$ bloodstream forms of $T$. b. rhodesiense STIB 900 in $50 \mu \mathrm{L}$ was added to each well and the plate incubated at $37{ }^{\circ} \mathrm{C}$ under a $5 \% \mathrm{CO}_{2}$ atmosphere for $72 \mathrm{~h} .10 \mu \mathrm{L}$ of a resazurin solution $(12.5 \mathrm{mg}$ resazurin dissolved in $100 \mathrm{~mL}$ double-distilled water) was then added to each well and incubation continued for a further 2-4 h. Then the plates were read in a Spectramax Gemini XS microplate fluorometer (Molecular Devices Cooperation, Sunnyvale, CA, USA) using an excitation wavelength of $536 \mathrm{~nm}$ and an emission wavelength of $588 \mathrm{~nm}$. Data were analyzed using the microplate reader software Softmax Pro (Molecular Devices Cooperation, Sunnyvale, CA, USA). Each IC 50 value obtained is the mean of at least two separate experiments performed in duplicate (the variation is maximum 20\%).

\subsection{Activity against Trypanosoma cruzi}

Rat skeletal myoblasts (L6 cells) were seeded in 96-well microtitre plates at 2000 cells/well in $100 \mu \mathrm{L}$ RPMI 1640 medium with 10\% FBS and $2 \mathrm{mM} \mathrm{1-glutamine.} \mathrm{After} 24 \mathrm{~h}$ the medium was removed and replaced by $100 \mu \mathrm{l}$ per well containing 5000 trypomastigote forms of $T$. cruzi Tulahuen strain $\mathrm{C} 2 \mathrm{C} 4$ containing the $\beta$-galactosidase (Lac Z) gene [27]. After $48 \mathrm{~h}$, the medium was removed from the wells and replaced by $100 \mu \mathrm{l}$ fresh medium with or without a serial drug dilution of seven 3 -fold dilution steps covering a range from 90 to $0.123 \mu \mathrm{g} / \mathrm{mL}$. After $96 \mathrm{~h}$ of incubation the plates were inspected under an inverted microscope to assure growth of the controls and sterility. Then the substrate CPRG/Nonidet ( $50 \mu \mathrm{l}$ ) was added to all wells. A color reaction developed within $2-6 \mathrm{~h}$ and could be read photometrically at $540 \mathrm{~nm}$. Data were transferred into the graphic programme Softmax Pro (Molecular Devices), which calculated $\mathrm{IC}_{50}$ values. Each $\mathrm{IC}_{50}$ value obtained is the mean of at least two separate experiments performed in duplicate (the variation is max. 20\%). Benznidazole was the standard drug used.

\subsection{Activity against Leishmania donovani}

Amastigotes of L. donovani strain MHOM/ET/67/L82 were grown in axenic culture at $37{ }^{\circ} \mathrm{C}$ in SM medium at $\mathrm{pH} 5.4$ supplemented with $10 \%$ heat-inactivated fetal bovine serum under an atmosphere of $5 \% \mathrm{CO}_{2}$ in air. One hundred $\mu \mathrm{L}$ of culture medium with $10^{5}$ amastigotes from axenic culture with or without a serial drug dilution were seeded in 96-well microtiter plates. Serial drug dilutions covering a range from 90 to $0.123 \mu \mathrm{g} / \mathrm{mL}$ were prepared. After $72 \mathrm{~h}$ of incubation the plates were inspected under an inverted microscope to assure growth of the controls and sterile conditions. $10 \mu \mathrm{L}$ of a resazurin solution (12.5 mg resazurin dissolved in $100 \mathrm{~mL}$ double-distilled water) [28] was then added to each well and the plates incubated for another $2 \mathrm{~h}$. Then the plates were read in a Spectramax Gemini XS microplate fluorometer using an excitation wavelength of $536 \mathrm{~nm}$ and an emission wavelength of 
$588 \mathrm{~nm}$. Data were analyzed using the software Softmax Pro. Decrease of fluorescence (=inhibition) was expressed as percentage of the fluorescence of control cultures and plotted against the drug concentrations. From the sigmoidal inhibition curves the $\mathrm{IC}_{50}$ values were calculated. Each $\mathrm{IC}_{50}$ value obtained is the mean of at least two separate experiments performed in duplicate (the variation is max. $20 \%$ ). Miltefosine was used as a reference drug.

\subsection{Cytotoxicity against L6-cells}

Assays were performed in 96-well microtiter plates, each well containing $100 \mu \mathrm{L}$ of RPMI 1640 medium supplemented with $1 \%$ L-glutamine $(200 \mathrm{mM})$ and $10 \%$ fetal bovine serum, and $4 \times 10^{4} \mathrm{~L}-6$ cells (a primary cell line derived from rat skeletal myoblasts). Serial drug dilutions of seven 3-fold dilution steps covering a range from 90 to $0.123 \mu \mathrm{g} / \mathrm{mL}$ were prepared. After $72 \mathrm{~h}$ of incubation the plates were inspected under an inverted microscope to assure growth of the controls and sterile conditions. $10 \mu \mathrm{l}$ of a resazurin solution ( $12.5 \mathrm{mg}$ resazurin dissolved in $100 \mathrm{~mL}$ distilled water) was then added to each well and the plates incubated for another $2 \mathrm{~h}$. Then the plates were read with a Spectramax Gemini XS microplate fluorometer using an excitation wavelength of $536 \mathrm{~nm}$ and an emission wavelength of $588 \mathrm{~nm}$. Data were analyzed using the microplate reader software Softmax Pro. Each $\mathrm{CC}_{50}$ value obtained is the mean of at least two separate experiments performed in duplicate. Podophyllotoxin was the standard drug used.

\subsection{PfFAS-II enzyme inhibition assays}

Expression and purification of the $P f F a b$ enzymes as well as the assays were performed as described [29]. The enzyme inhibition was monitored using a Perkin Elmer Envision 2101 Multilabel Reader. Measurements were carried out in Nundron Surface sterile 96-well plates, using $20 \mathrm{mM}$ Hepes and $150 \mathrm{mM} \mathrm{NaCl}$ at $\mathrm{pH}$ 7.4. Compounds were dissolved in DMSO (maximum final concentration $1 \%$ ). A dilution series of $50 \mu \mathrm{g} / \mathrm{mL}$ to $0.0005 \mu \mathrm{g} / \mathrm{mL}$ of dissolved compounds was measured. For PfFabI, $400 \mu \mathrm{M}$ NADH (cofactor, Sigma) was added to $2 \mu \mathrm{g}$ enzyme and reaction started by addition of $300 \mu \mathrm{M}$ crotonyl-CoA (substrate, Sigma). The change of absorbance of the mixture was recorded spectrophotometrically at $340 \mathrm{~nm}$ for 40 minutes. Triclosan was used as a positive control and was analyzed the same way. For PfFabG $400 \mu \mathrm{M}$ NADPH (cofactor, Fluka) was added to $0.5 \mu \mathrm{g}$ enzyme and reaction started by addition of $300 \mu \mathrm{M}$ acetoacetyl-CoA (substrate, Sigma). The change of absorbance of the mixture was recorded spectrophotometrically at $340 \mathrm{~nm}$ for 20 minutes. (-)-Epigallocatechin gallate (Sigma) was used as a positive control and was analyzed the same way. For $P f F a b Z, 600 \mu \mathrm{M}$ crotonoyl-CoA (substrate, Sigma) was added to $0.5 \mu \mathrm{g}$ enzyme. The change of absorbance of the mixture was recorded spectrophotometrically at $260 \mathrm{~nm}$ for 20 minutes. (-)-Epigallocatechin gallate was used as a positive control. $\mathrm{IC}_{50}$ values were estimated from graphically plotted dose-response curves. Each $\mathrm{IC}_{50}$ value obtained is the mean of at least two separate experiments performed in duplicate. 


\section{Conclusions}

The present study constitutes the first report on the wide-spectrum antiprotozoal activity of bromopyrrole alkaloids, one of the best known and chemically diverse classes of marine alkaloids. We have identified dispacamide B (3) and spongiacidin B (6) as antimalarial lead compounds, with significant activity and low or no toxicity towards mammalian cells. Our data indicated that dibromopalau'amine (11) and longamide B (8) are potent trypanocidal and antileishmanial agents, with narrower therapeutic windows. These lead compounds could be converted to more selective and more potent trypanocidal antiprotozoal drugs by medicinal chemistry approach. The preliminary structure-activity relationships deduced should encourage further studies aimed at investigating their mechanisms of action as well as at optimizing their antiprotozoal activities. The availability of tens of other natural bromopyrroles and the possibility of obtaining some non-natural derivatives through total synthesis (model total syntheses for dispacamide B [30] and longamide B [31] have been reported) could be particularly helpful to this aim.

\section{Acknowledgements}

This work was supported by MIUR (PRIN2008: Leads ad Attività Antimalarica di Origine Naturale: Isolamento, Ottimizzazione e Valutazione Biologica). Mass and NMR spectra were recorded at the "Centro di Ricerca Interdipartimentale di Analisi Strumentale" of the University of Naples "Federico II".

\section{References}

1. Data taken from Malaria Foundation International. http://www.malaria.org and linked sites. (accessed on 3 May 2010).

2. Brun, R.; Blum, J.; Chappuis, F.; Burri, C. Human African trypanosomiasis. Lancet 2010, 375, $148-159$.

3. Bern, C.; Maguire, J.H.; Alvar, J. Complexities of Assessing the Disease Burden Attributable to Leishmaniasis. PLoS Neglect. Trop. D 2008, 2, e313.

4. Reithinger, R. Leishmaniases' burden of disease: ways forward for getting from speculation to reality. Plos Neglect. Trop. D 2008, 2, e285.

5. Fattorusso, E.; Taglialatela-Scafati, O. Marine Antimalarials. Mar. Drugs 2009, 7, 130-152.

6. Mayer, A.M.; Rodriguez, A.D.; Berlinck, R.G.; Hamann, M.T. Marine pharmacology in 2005-6: Marine compounds with anthelmintic, antibacterial, anticoagulant, antifungal, anti-inflammatory, antimalarial, antiprotozoal, antituberculosis, and antiviral activities; affecting the cardiovascular, immune, and nervous systems and other miscellaneous mechanisms of action. Biochim. Biophys. Acta 2009, 1790, 283-308.

7. Tasdemir, D.; Topaloglu, B.; Perozzo, R.; Brun, R.; O’Neill, R.; Carballeira, N.M.; Zhang, X.; Tonge, P.J.; Linden, A.; Ruedi, P. Marine natural products from the Turkish sponge Agelas oroides that inhibit the enoyl reductases from Plasmodium falciparum, Mycobacterium tubercolosis and Escherichia coli. Bioorg. Med. Chem. 2007, 15, 6834-6845. 
8. Waller, R.F.; Keeling, P.J.; Donald, R.G.; Striepen, B.; Handman, E.; Lang-Unnasch, N.; Cowman, A.F.; Besra, G.S.; Roos, D.S.; McFadden, G.I. Nuclear-encoded proteins target to the plastid in Toxoplasma gondii and Plasmodium falciparum. Proc. Natl. Acad. Sci. USA 1998, 95, 12352-12357.

9. Surolia, N.; Surolia, A. Triclosan offers protection against blood stages of malaria by inhibiting enoyl-ACP reductase of Plasmodium falciparum. Nat. Med. 2001, 7, 167-173.

10. Vaughan, A.M.; O'Neill, M.T.; Tarun, A.S.; Camargo, N.; Phuong, T.M.; Aly, A.S.; Cowman, A.F.; Kappe, S.H. Type II fatty acid synthesis is essential only for malaria parasite late liver stage development. Cell. Microbiol. 2009, 11, 506-520.

11. Yu, M.; Kumar, T.R.; Nkrumah, L.J.; Coppi, A.; Retzlaff, S.; Li, C.D.; Kelly, B. J.; Moura, P.A.; Lakshmanan, V.; Freundlich, J.S.; Valderramos, J.C.; Vilcheze, C.; Siedner, M.; Tsai, J.H.; Falkard, B.; Sidhu, A.B.; Purcell, L.A.; Gratraud, P.; Kremer, L.; Waters, A.P.; Schiehser, G.; Jacobus, D.P.; Janse, C.J.; Ager, A.; Jacobs, W.R., Jr.; Sacchettini, J.C.; Heussler, V.; Sinnis, P.; Fidock, D.A. The fatty acid biosynthesis enzyme FabI plays a key role in the development of liver-stage malarial parasites. Cell Host Microbe 2008, 4, 567-578.

12. Aiello, A.; Fattorusso, E.; Menna, M.; Taglialatela-Scafati, O. In Modern Alkaloids; Fattorusso, E., Taglialatela-Scafati, O., Eds.; Wiley-VCH: Weinheim, Germany, 2007; pp. 271-304.

13. Kobayashi, J.; Suzuki, M.; Tsuda, M. Konbu'acidin A, a new bromopyrrole alkaloid with cdk4 inhibitory activity from Hymeniacidon sponge. Tetrahedron 1997, 53, 15681-15684.

14. Cafieri, F.; Fattorusso, E.; Mangoni, A.; Taglialatela-Scafati, O. Dispacamides, anti-histamine alkaloids from Caribbean Agelas sponges. Tetrahedron Lett. 1996, 37, 3587-3590.

15. Cafieri, F.; Carnuccio, R.; Fattorusso, E.; Taglialatela-Scafati, O.; Vallefuoco, T. Anti-histaminic activity of bromopyrrole alkaloids isolated from Caribbean Agelas sponges. Bioorg. Med. Chem. Lett. 1997, 7, 2283-2288.

16. Kobayashi, J.; Ohizumi, Y.; Nakamura, H.; Hirata, Y. A novel antagonist of serotonergic receptors, hymenidin, isolated from the Okinawan marine sponge Hymeniacidon species. Experientia 1986, 42, 1176-1177.

17. Cafieri, F.; Fattorusso, E.; Mangoni, A.; Taglialatela-Scafati, O. A novel bromopyrrole alkaloid from the sponge Agelas longissima with antiserotonergic activity. Bioorg. Med. Chem. Lett. 1995, 5, 799-804.

18. Kinnel, R.B.; Gehrken, H.P.; Scheuer, P.J. Palau'amine: a cytotoxic and immunosuppressive hexacyclic bisguanidine antibiotic from the sponge Stylotella agminata. J. Am. Chem. Soc. 1993, 115, 3376-3377.

19. Walker, R.P.; Faulkner, D.J.; van Engen, D.; Clardy, J. Sceptrin, an antimicrobial agent from the sponge Agelas sceptrum. J. Am. Chem. Soc. 1981, 103, 6772-6773.

20. Cipres, A.; O'Malley, D.P.; Li, K.; Finlay, D.; Baran, P.S.; Vuori, K. Sceptrin, a Marine Natural Compound, Inhibits Cell Motility in a Variety of Cancer Cell Lines. ACS Chem. Biol. 2010, 5 , 195-202.

21. Aiello, A.; D'Esposito, M.; Fattorusso, E.; Menna, M.; Mueller, W.E.G.; Perovic-Ottstadt, S.; Schroeder, H.C. Novel bioactive bromopyrrole alkaloids from the Mediterranean sponge Axinella verrucosa. Bioorg. Med. Chem. 2006, 14, 17-24. 
22. Cafieri, F.; Fattorusso, E.; Mangoni, A.; Taglialatela-Scafati, O. Longamide and 3,7-dimethylisoguanine, two novel alkaloids from the marine sponge Agelas longissima. Tetrahedron Lett. 1995, 36, 7893-7896.

23. Cafieri, F.; Fattorusso, E.; Taglialatela-Scafati, O. Novel bromopyrrole alkaloids from the sponge Agelas dispar. J. Nat. Prod. 1998, 61, 122-125.

24. Matile, H.; Pink, J.R.L. In Immunological Methods; Lefkovits, I., Pernis, B., Eds.; Academic Press: San Diego, CA, USA, 1990; pp. 221-234.

25. Baltz, T.; Baltz, D.; Giroud, C.; Crockett, J. Cultivation in a semi-defined medium of animal infective forms of Trypanosoma brucei, T. equiperdum, T. evansi, T. rhodesiense and T. gambiense. ЕМВО J. 1985, 4, 1273-1277.

26. Thuita, J.K.; Karanja, S.M.; Wenzler, T.; Mdachi, R.E.; Ngotho, J.M.; Kagira, J.M.; Tidwell, R.; Brun, R. Efficacy of the diamidine DB75 and its prodrug DB289, against murine models of human African trypanosomiasis. Acta Trop. 2008, 108, 6-10.

27. Buckner, F.S.; Verlinde, C.L.; La Flamme, A.C.; van Voorhis, W.C. Efficient technique for screening drugs for activity against Trypanosoma cruzi using parasites expressing betagalactosidase. Antimicrob. Agents Chemother. 1996, 40, 2592-2597.

28. Mikus, J.; Steverding, D. A simple colorimetric method to screen drug cytotoxicity against Leishmania using the dye Alamar Blue. Parasitol. Int. 2000, 48, 265-269.

29. Tasdemir, D.; Lack, G.; Brun, R.; Rüedi, P.; Scapozza, L.; Perozzo, R. Inhibition of Plasmodium falciparum fatty acid biosynthesis: evaluation of FabG, FabZ, and FabI as drug targets for flavonoids. J. Med. Chem. 2006, 49, 3345-3353.

30. Fresneda, P.M.; Molina, P.; Sanz, M.A. A convergent approach to midpacamide and dispacamide pyrrole-imidazole marine alkaloids. Tetrahedron Lett. 2001, 42, 851-854.

31. Sun, X.-T.; Chen, A. Total synthesis of rac- longamide B. Tetrahedron Lett. 2007, 48, 3459-3461.

Samples Availability: Available from the authors.

(C) 2010 by the authors; licensee MDPI, Basel, Switzerland. This article is an Open Access article distributed under the terms and conditions of the Creative Commons Attribution license (http://creativecommons.org/licenses/by/3.0/). 